\title{
Karyotype evolution in progress: A new diploid number in Belostoma candidulum (Heteroptera: Belostomatidae) from Argentina leading to new insights into its ecology and evolution
}

\author{
MóNICA G. CHIRINO ${ }^{1,2}$ and MARÍA J. BRESSA ${ }^{1}$ \\ ${ }^{1}$ Instituto de Ecología, Genética y Evolución de Buenos Aires, Departamento de Ecología, Genética y Evolución, Facultad \\ de Ciencias Exactas y Naturales, Universidad de Buenos Aires, Ciudad Universitaria, Pabellón II, C1428EHA, Ciudad Autónoma \\ de Buenos Aires, Argentina; e-mails: mchirino@ege.fcen.uba.ar; mjbressa@ege.fcen.uba.ar \\ ${ }^{2}$ Laboratorio de Entomología Aplicada y Forense, Departamento de Ciencia y Tecnología, Universidad Nacional de Quilmes, Roque \\ Sáenz Peña 352, B1876BXD, Bernal, Buenos Aires, Argentina
}

Key words. Heteroptera, Belostomatidae, Belostoma candidulum, holokinetic chromosomes, ring bivalents, chromosomal races, cryptic species, karyotype evolution, rDNA-FISH

\begin{abstract}
A novel chromosome complement $(2 \mathrm{n}=14=12+\mathrm{XY} / \mathrm{XX}$; male/female sex chromosomes), male meiosis behaviour, heterochromatin characterization, and frequency and distribution of chiasmata are described for the first time in specimens from a natural population of the giant water bug, Belostoma candidulum Montandon, 1903 (Heteroptera: Belostomatidae) from Argentina. To date, specimens of B. candidulum have been reported by other authors in a sample from a natural population from Brazil. Our results demonstrate that Argentinean and Brazilian populations have different diploid numbers and chromosomal features. During male meiosis, autosomal bivalents generally show a single chiasma, behave as telokinetic chromosomes (i.e. kinetic activity is restricted to terminal regions), and divide reductionally at anaphase I; in contrast, the sex chromosomes are achiasmatic, behave as univalents and segregate equationally at anaphase I. Among autosomal bivalents of $B$. candidulum, one is remarkably larger and may present one or two terminal chiasmata, showing rod, V-shaped and ring configurations. Here we propose a new mode of segregation for ring bivalents, since it is not essential that one of the chiasmata is released during anaphase I because alternative sites for microtubule attachment become functional for the normal chromosome segregation to the poles. Heterochromatin content is very scarce in specimens from Argentinean B. candidulum populations, revealing C-positive interstitial and terminal dots in three pairs of autosomes and C-blocks at both ends of $\mathrm{X}$ chromosome, whereas the $\mathrm{Y}$ chromosome is mainly C-positive. One of the C-positive bands from X and Y chromosomes is DAPIdull/CMA-bright, which could represent the nucleolus organizing region (NOR) detected by fluorescent in situ hybridization (FISH). The location of the NORs in both sex chromosomes allowed us to use them as a cytological marker to describe their behaviour during meiosis. Despite the fact that specimens from the Argentinean and Brazilian populations have been classified as a single species due to their morphological similarity, our results suggest that both populations are chromosomal races or even morphologically-identical cryptic species. The results obtained support the hypothesis that karyotype of $B$. candidulum originated through autosomal fusions and the fusion of the $\mathrm{X}$ and $\mathrm{Y}$ chromosomes with the ancestral NOR-autosomal pair. Lastly, the genus Belostoma represents an excellent model for assessing the main mechanisms involved in the karyotype evolution in organisms with holokinetic chromosomes, from which inferences may be made concerning its broader ecology and evolution.
\end{abstract}

\section{INTRODUCTION}

The insect genus Belostoma Latreille, 1807 (Heteroptera: Belostomatidae) includes 61 nominal species and is the most diverse genus of Belostomatidae in tropical and subtropical areas in South America, as well as occurring elsewhere worldwide (cf. Schnack, 1976; Polhemus \& Polhemus, 2008; Heckman, 2011). Cytogenetic analyses of the South American species reveal that the chromosome complement $2 \mathrm{n}=26+\mathrm{X}_{1} \mathrm{X}_{2} \mathrm{Y} / \mathrm{X}_{1} \mathrm{X}_{1} \mathrm{X}_{2} \mathrm{X}_{2}$ (male/female sex chromosomal complement) represents the modal chromosome number (10 species), although species with reduced diploid numbers are reported: $2 \mathrm{n}=14+\mathrm{XY} / \mathrm{XX}$ (four species) and $2 \mathrm{n}=6+\mathrm{XY} / \mathrm{XX}$ (one species) (Papeschi \& Bressa, 2006; Bardella et al., 2012; Chirino et al., 2013).

All Belostoma species studied share similar cytogenetic characteristics: (a) presence of holokinetic chromosomes, i.e. without a primary constriction; (b) occurrence of synizesis (meiotic chromatin condenses eccentrically on one side of the nucleous; McClung, 1905) and diffuse stage; (c) a telokinetic activity in meiosis and a holokinetic activity in mitosis; (d) autosomal bivalents are synaptic and chiasmatic, whereas sex chromosomes are asynaptic and achiasmatic; (e) smallest bivalents have a single chiasma and the largest possess one or two chiasmata; (f) autosomal bivalents segregate reductionally and sex chromosomes divide equationally in the first meiotic division; ( $g$ ) an inverse relationship between chromosome number and chromosome size, with autosomal bivalents decreasing in size; (h) an inverse relationship between total chromosome length (TCL) and DNA content and C-banding pattern; and (i) in species with reduced chromosome numbers and a simple sex chromosome system (XY/XX), the nucleolus organizing region (NOR) is located in both sex chromosomes, whereas in species with the modal diploid number of autosomes (26) and a multiple sex chromosome system $\left(\mathrm{X}_{1} \mathrm{X}_{2} \mathrm{Y} / \mathrm{X}_{1} \mathrm{X}_{1} \mathrm{X}_{2} \mathrm{X}_{2}\right)$, it is located in a pair of homologous 
autosomes (Ueshima, 1979; Motzko \& Ruthmann, 1984; Papeschi \& Bidau, 1985; Papeschi, 1988, 1992, 1994, 1996; Suja et al., 2000; Papeschi \& Bressa, 2006; Bardella et al., 2012; Chirino et al., 2013).

The last cytogenetic characteristic described above allowed us to propose an ancestral male karyotype $2 \mathrm{n}=26+$ $\mathrm{XY}$ sex chromosomes for Belostoma, in which the NOR is located in one pair of autosomes, and involving two paths of karyotype evolution: (i) a fragmentation of the single ancestral $\mathrm{X}$ chromosome derived in a multiple sex chromosome system which led to a karyotype $2 \mathrm{n}=26+\mathrm{X}_{1} \mathrm{X}_{2} \mathrm{Y}$, with retention of the ancestral NOR-autosome pair; and (ii) several autosomal fusions plus the fusion of the ancestral sex chromosome pair with the NOR-autosome pair resulting in reduced chromosome numbers $(2 n=14+X Y, 2 n=$ $6+\mathrm{XY})$, and increase of chromosome size, and which led to the presence of ribosomal DNA (rDNA) clusters in both $\mathrm{X}$ and $\mathrm{Y}$ chromosomes (Papeschi \& Bressa, 2006; Chirino et al., 2013).

In the present study, a novel chromosome complement found in specimens taken from a natural population of $\mathrm{Be}$ lostoma candidulum Montandon, 1903 from Argentina is described for the first time. The male and female karyotypes, the male meiosis behaviour, and frequency and distribution of chiasmata were studied. The content, location and distribution of heterochromatin were analysed by $\mathrm{C}$ and fluorescent banding. Using fluorescence in situ hybridization (FISH) with the $18 \mathrm{~S}$ rDNA probe, we localized the position of the NORs and showed that the presence of these in both sex chromosomes allowed us to use them as a cytological marker to describe their behaviour during meiosis.

Belostoma represents an excellent model for evolutionary cytogenetic studies since this genus shows great interespecific variation in the diploid chromosome number, many chromosome changes and interespecific differences in the DNA content. The presence of a novel chromosome complement allows increased insight into the evolution of the karyotypes including the role of chromosome fusions in the genus Belostoma.

\section{MATERIAL AND METHODS}

\section{Insects}

We used four males and two females of $B$. candidulum, collected in 2010 and 2011 at the El Palmar National Park, Entre Ríos Province, Argentina $\left(31^{\circ} 54^{\prime} \mathrm{S}, 58^{\circ} 15^{\prime} \mathrm{W}\right)$. Taxonomic determination of the specimens was performed by Ana L. Estévez (Facultad de Ciencias Naturales y Museo, Universidad Nacional de La Plata) (Ribeiro \& Estévez, 2009). Male and female specimens of Argentinean cytotypes of $B$. candidulum were deposited in the Museo Argentino de Ciencias Naturales "Bernardino Rivadavia" (MACN, Buenos Aires, Argentina) by Arturo Roig Alsina (Entomology Division).

\section{Chromosome preparations}

The specimens were brought alive to the laboratory and their gonads dissected out in a physiological saline solution as earlier described for the pyralid moth, Ephestia sp. Guenée, 1845 (Glaser, 1917: cited by Lockwood, 1961), swollen in a hypotonic solution and fixed as described in Chirino et al. (2013). For mitotic and meiotic analysis, gonads were kept at $4{ }^{\circ} \mathrm{C}$ in $70 \%$ ethanol and slides were prepared by the squash technique in a drop of $2 \%$ acetic-haematoxylin (Sáez, 1960). For C- and fluorescent banding and the FISH technique, spread chromosome preparations were made from the testes and ovaries of male and female adults. Cells were dissociated in a drop of $60 \%$ acetic acid with the help of tungsten needles and spread on the slide using a heating plate at $45^{\circ} \mathrm{C}$ as described in Traut (1976). The preparations were dehydrated in an ethanol series (70, 80 and $96 \%, 30 \mathrm{~s}$ each) and stored at $-20^{\circ} \mathrm{C}$ until use.

\section{Chromosome bandings}

Heterochromatin content, distribution and nucleotide composition were analysed by means of $\mathrm{C}$ - and sequential fluorescent DAPI (4',6-diamidino-2-phenylindole) and $\mathrm{CMA}_{3}$ (chromomycin A3) banding. Details of the methods used are discussed in greater depth and broadly follow those as detailed in Papeschi (1988) and Poggio et al. (2011).

\section{Fluorescence in situ hybridization}

Unlabelled 18S ribosomal DNA (rDNA) probes, derived from genomic DNA of the true bug, Dysdercus albofasciatus Berg, 1878 (Heteroptera: Pyrrhocoridae), were obtained and labelled with biotin 14-dATP by nick translation using a BioNick Labeling System (Invitrogen, Life Technologies Inc., San Diego, CA, USA) as described in Fuková et al. (2005), Bressa et al. (2009) and Chirino et al. (2013). FISH with a biotinylated 18S rDNA probes was performed following the procedure in Sahara et al. (1999) with several modifications described by Fuková et al. (2005) and Bressa et al. (2009). Hybridization signals were detected with Cy3-conjugated streptavidin (Jackson ImmunoRes. Labs. Inc., West Grove, PA, USA).

\section{Statistical analysis}

Suitable cells at the meiotic metaphase were selected and the mean descriptive values of the karyotype calculated using information obtained from 88 cells. The total chromosome length measurements (TCL), relative average length ( $\mu \mathrm{m}$; length of an autosomal bivalent as a percentage of the TCL) and relative chromosomal percentage (\%) were performed with Micro Measure for Windows, version 3.3 (Reeves \& Tear, 2000). Measurements of autosomal bivalents and sex chromosomes were performed in metaphase I. Differences in relative average length and relative chromosomal percentage were analysed using the KruskallWallis ANOVA test on ranks for global comparisons $(P<0.05)$, followed by Mann-Whitney U tests for contrasts between treatments, since the data were not normally distributed (Daniel, 1990). The presence of one ring, rod or V-shaped bivalent (of the largest autosomal pair) was frequently observed in 153 cells from three males. Configuration frequencies of the largest bivalent were analysed by means of Chi-squared goodness of fit to be distributed at diplotene, diakinesis and metaphase I stages. The location of NORs in the XY pseudo-bivalent at metaphase II, in which the kinetically active or inactive, was tested in 46 cells from three males using a Chi-squared goodness of fit test to determine whether or not the kinetic behaviour is a random process. Statistical analyses were done using Statistix for Windows, version 2.0 (Analytic Software, 1998).

\section{Microscopy, photographs and image processing}

Preparations were observed under high power magnification using a Leica DMLB epifluorescence microscope equipped with a Leica DFC350 FX CCD camera and Leica IM50 software, version 4.0 (Leica Microsystems Imaging Solutions Ltd., Cambridge, UK). Black-and-white images of chromosomes were recorded separately for each fluorescent dye with the CCD camera. Images were pseudo-coloured (light blue for DAPI, green 


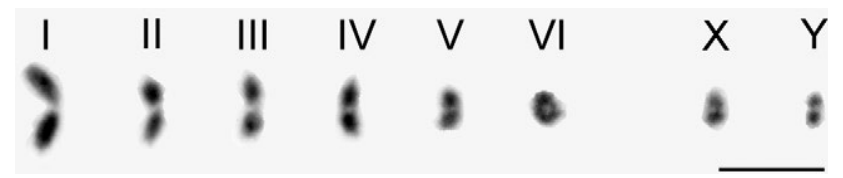

Fig. 1. Male meiotic karyotype of B. candidulum, $\mathrm{n}=6 \mathrm{II}+\mathrm{XY}$, stained with $2 \%$ acetic haematoxylin. II $=$ autosomal bivalent. Bar $=10 \mu \mathrm{m}$.

for $\mathrm{CMA}_{3}$, and red for $\mathrm{Cy} 3$ ), and processed with the appropriate software.

\section{RESULTS}

\section{Chromosome complement and meiosis}

The chromosome complement of $B$. candidulum is $2 \mathrm{n}$ $=14=12+\mathrm{XY} / \mathrm{XX}$ (male/female sex chromosmes) and has a total chromosome length (TCL) of $28.5 \pm 5.2 \mu \mathrm{m}$. An autosomal pair is easily identified due to its large size among the remaining five pairs of autosomes that gradually decrease in size (Table 1). The $\mathrm{X}$ chromosome is medium sized and the $\mathrm{Y}$ is the smallest of the complement (Figs 1, $2 \mathrm{a}-\mathrm{b}$; Table 1). In mitotic prometaphase in both sexes, the $\mathrm{X}$ chromosomes have a secondary constriction (Fig. 2a-b). During mitotic anaphase, the sister chromatids migrate in parallel to the spindle poles, in contrast to meiosis where the kinetic activity is restricted to the chromosome ends, and the chromosomes can be regarded as telokinetic (Fig. 2c).

The meiotic behaviour was similar to that previously described for other Belostoma species. Pairing occurred at synizesis, and at pachytene both sex chromosomes, close to each other, were condensed and the 6 autosomal bivalents were joined through their terminal regions (Fig. 2d). At the diffuse stage, all bivalents de-condensed completely and the sex chromosomes were seen to be positively heteropyknotic, almost always associated but usually individually recognisable (Fig. 2e). From diplotene onwards, 6 bivalents and two sex chromosomes univalents were clearly discernible (Fig. 2f). At early diakinesis, both sex chromosomes were negatively heteropyknotic (data not shown). During late diakinesis, the 6 autosomal bivalents became isopyknotic and the $\mathrm{X}$ and $\mathrm{Y}$ sex univalents were negatively heteropyknotic (Fig. 2g-i). At metaphase I, autosomal bivalents were arranged in a ring, but the $\mathrm{X}$ and $\mathrm{Y}$ univalents did not show a defined position (Fig. 2j, k). Anaphase I was reductional for autosomes and equational for sex chromosomes. All telophase I nuclei exhibited 8 chromosomes in each pole $(6+\mathrm{XY}$; data not shown). The second meiotic division followed without an interkinesis stage. In metaphase II, the XY pseudo-bivalent was local-
TABLE 1. Comparison of the male meiotic size of chromosomes $(2 \mathrm{n}=12+\mathrm{XY})$ during metaphase I of $B$. candidulum.

\begin{tabular}{lcc}
\hline Chromosomes & Average length $(\mu \mathrm{m})^{1}$ & Relative length $(\%)^{1}$ \\
\hline Bivalent I & $7.2 \pm 1.6 \mathrm{a}$ & $25.3 \pm 2.3 \mathrm{a}$ \\
Bivalent II & $4.9 \pm 1.0 \mathrm{~b}$ & $17.1 \pm 1.1 \mathrm{~b}$ \\
Bivalent III & $4.3 \pm 0.8 \mathrm{bc}$ & $15.2 \pm 1.0 \mathrm{bc}$ \\
Bivalent IV & $3.9 \pm 0.8 \mathrm{~cd}$ & $13.6 \pm 1.3 \mathrm{~cd}$ \\
Bivalent V & $3.2 \pm 0.6 \mathrm{de}$ & $11.4 \pm 1.4 \mathrm{de}$ \\
Bivalent VI & $2.5 \pm 0.6 \mathrm{ef}$ & $8.9 \pm 1.7 \mathrm{ef}$ \\
X chromosome & $1.6 \pm 0.6 \mathrm{fg}$ & $6.4 \pm 0.9 \mathrm{fg}$ \\
Y chromosome & $0.8 \pm 0.3 \mathrm{~h}$ & $2.9 \pm 0.6 \mathrm{~h}$ \\
\hline
\end{tabular}

${ }^{1}$ The comparisons of chromosomal lengths (mean $\left.\pm \mathrm{SE}, \mu \mathrm{m}\right)$ and the relative chromosomal percentage (mean $\pm \mathrm{SE}, \%$ ) were made using a one-way Kruskall-Wallis test $(H=680.21, \mathrm{df}=7,696, P$ $<0.0001$ for chromosomal lengths measurements; $H=659.44$, $\mathrm{df}=7,696, P<0.0001$ for relative chromosomal lengths measurements). Different letters indicate significant differences $(P<$ $0.05)$.

ized in the middle of the autosomal ring (Fig. 21). Both sex chromosomes were negatively heteropyknotic and they were oriented towards the opposite spindle pole. At anaphase II, 7 chromosomes migrated to one pole $(6+\mathrm{Y}$ and 6 $+\mathrm{X}$; data not shown).

The largest autosomal bivalent showed one or two chiasmata at terminal position (Fig. 2f-k). Three kinds of bivalents were frequently observed from diplotene to metaphase I: rod (autosomal bivalent with one chiasma; Fig. $2 \mathrm{f}, \mathrm{g}$ ), $\mathrm{V}$-shaped (autosomal bivalent that one of the two chiasmata releases first; Fig. 2h) and ring bivalents (autosomal bivalent with two chiasmata; Fig. $2 \mathrm{f}$, i). When the largest bivalent had two chiasmata, one of them released first, one pair of terminal regions became free to attach to the spindle, and the bivalent remained linked by the second chiasma, and took a V-shaped configuration (Fig. 2j). In other cells, the ring bivalent was stabilized at the metaphase plate with the longitudinal axes perpendicular to the polar axis and released the homologous chromosomes without liberating the two chiasmata at anaphase I, i.e. the ring bivalent separated as half rings, and kinetic activity involved sites other than the chromosome ends (Fig. 2k). The observed frequencies were significantly different from expected assuming random segregation because the presence of one rod or ring bivalent was mainly observed, while the V-shaped bivalent was even rarer (Table 2). Rod and ring arrangements showed very little variation from diplotene to metaphase I, since the largest bivalent had one or two terminal chiasmata at the same frequency. Thus in general, it does not appear essential that one of the chiasmata is

TABLE 2. Frequency of cells at the diplotene, diakinesis and metaphase I stages in which the first bivalent exhibited rod, V-shaped and ring configurations.

\begin{tabular}{lcccccc}
\hline \multirow{2}{*}{ Phase } & \multirow{2}{*}{ No. of cells } & \multicolumn{3}{c}{ Bivalent configurations } & \multirow{2}{*}{$\chi^{2}$} & \multirow{2}{*}{$P$} \\
\cline { 3 - 5 } & & Rod & V-shaped & Ring & & 0.0125 \\
\hline Diplotene & 46 & $33(71.7 \%)$ & $0(0.0 \%)$ & $13(28.3 \%)$ & & 12.756 \\
Diakinesis & 49 & $23(46.9 \%)$ & $7(14.3 \%)$ & $19(38.8 \%)$ & & \\
Metaphase I & 58 & $25(43.1 \%)$ & $6(10.3 \%)$ & $27(46.6 \%)$ & & \\
\hline
\end{tabular}



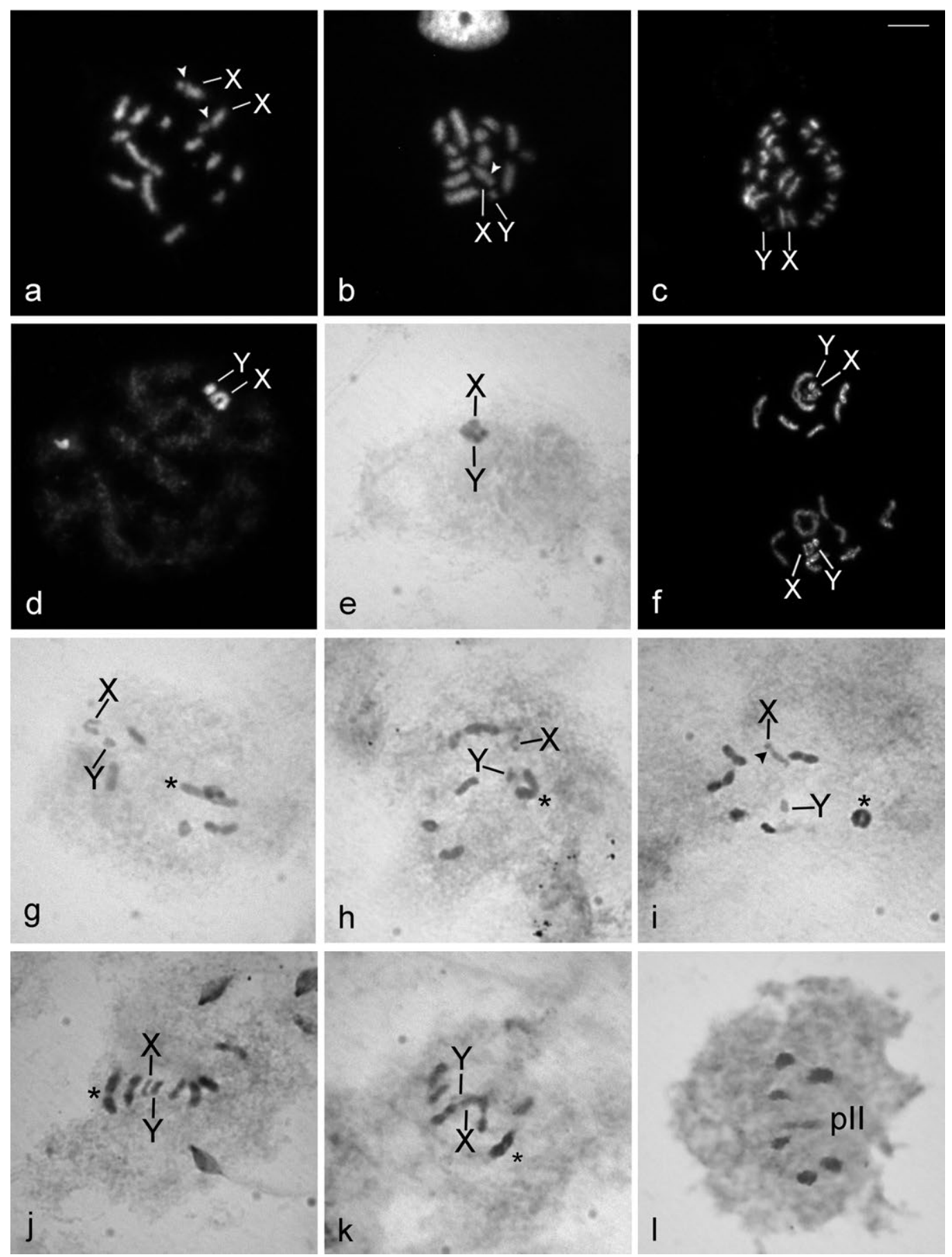

Fig. 2. Female and male mitosis and male meiosis in B. candidulum stained with $2 \%$ acetic haematoxylin (e, g-1) and DAPI (a-d, f) $\mathrm{a}$ - oogonial prometaphase; $\mathrm{b}$ - spermatogonial prometaphase; $\mathrm{c}$ - spermatogonial anaphase; $\mathrm{d}$ - pachytene; $\mathrm{e}$ - diffuse stage; $\mathrm{f}$ - diplotene with largest bivalent with one (up) or two (below) chiasmata; g-i - early diakinesis with rod (g), V-shaped (h) and ring (i) largest bivalents; $\mathrm{j}-\mathrm{k}$ - metaphase I with rod (j) and ring (k) largest bivalents; 1 - metaphase II, pseudo-bivalent is negatively heteropycnotic. $\mathrm{X}, \mathrm{Y}=$ sex chromosomes. Arrowheads show the secondary constriction in the $\mathrm{X}$ chromosomes. Asterisks indicate the largest autosomal bivalent with one or two chiasmata in terminal position. $\mathrm{pII}=$ pseudo-bivalent. $\mathrm{Bar}=10 \mu \mathrm{m}$.

released previously in order to stabilize the ring bivalent at the metaphase plate (Table 2).

\section{Chromosome bandings}

Heterochromatin content was very scarce in all specimens of $B$. candidulum and C-banding revealed very little interstitial and terminal dots in three autosomal bivalents tested (Fig. 3a-c). A single nucleolus was present, visible as a negative heteropyknotic body, which was invariably associated with one of the sex chromosomes (Fig. 3d). The $\mathrm{X}$ chromosome showed two terminally located blocks, whereas the Y chromosome was mainly C-positive (Fig. 3d-e). After diakinesis, the C-positive dots and blocks were not observed (Fig. 3f). Heterochromatic bands were neither AT nor GC rich as revealed by DAPI and $\mathrm{CMA}_{3}$ sequential fluorescent banding for any chromosome pair in 

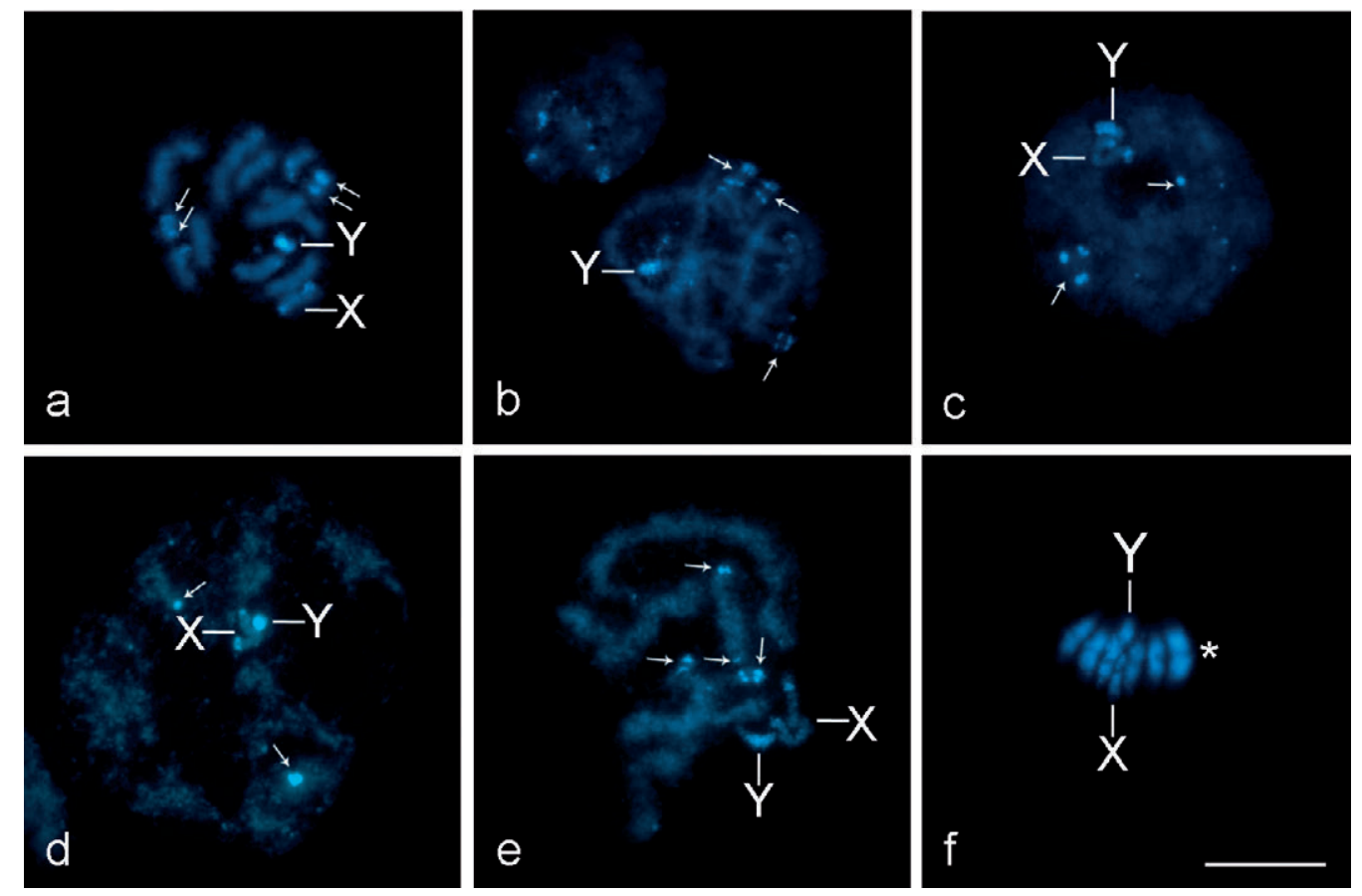

Fig. 3. C-banding in male chromosomes of B. candidulum. a - spermatogonial prometaphase; $\mathrm{b}$ - pachytene; $\mathrm{c}$ - diffuse stage; $\mathrm{d}$ - late diffuse stage; e - early diplotene; $\mathrm{f}$ - metaphase I. Arrows indicate C-positive interstitial and terminal dots and bands in three autosomal bivalents. $\mathrm{X}, \mathrm{Y}=$ sex chromosomes. Asterisk indicates the ring bivalent. Bar $=10 \mu \mathrm{m}$.

both mitotic and meiotic cells (Fig. 4), except for the $\mathrm{X}$ and Y chromosomes, which showed a DAPI-dull/CMA-bright band at one terminal position (Fig. 4).

\section{Location of rDNA}

FISH involving $18 \mathrm{~S}$ rDNA probes revealed two clusters of rDNA genes located at one end of both sex chromosomes on all phases of meiosis in a similar location to the DAPI-dull/CMA-bright band (Fig. 5a-d). This molecular marker was a sequence used to spot a particular location on both sex chromosomes during the second meiotic division.
The presence in both sex chromosomes of one rDNA cluster at only one chromosomal end allowed determination of whether the kinetic behaviour occurring at both ends (and whether carrying the NOR or not) was a random process at metaphase II. At the second metaphase, the XY pseudobivalent showed four distinctive orientations: Type XY-1 (kinetic activity located at both ends with rDNA signal in both sex chromosomes; Fig. 5d), Type XY-2 (kinetic activity located at both ends without rDNA signal in both sex chromosomes; Fig. 5e), Type XY-3 (kinetic activity locat-
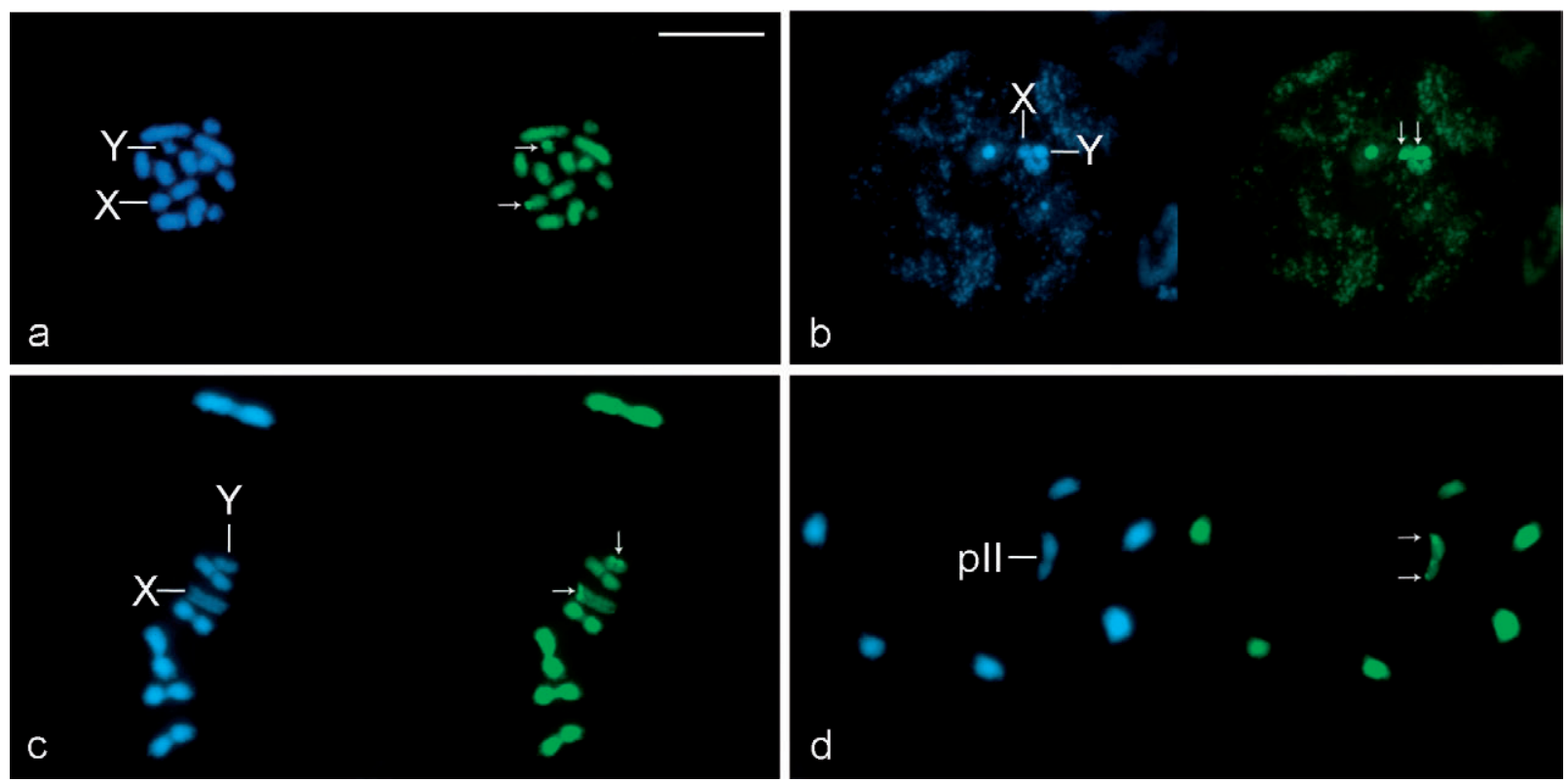

Fig. 4. DAPI (blue) and $\mathrm{CMA}_{3}$ (green) fluorescent banding in male chromosomes of $B$. candidulum. $\mathrm{a}$ - spermatogonial metaphase; $\mathrm{b}$ - late diffuse stage; $\mathrm{c}$ - diakinesis; $\mathrm{d}$ - metaphase II. Arrows indicate DAPI-dull/CMA-bright band. $\mathrm{pII}=$ pseudo-bivalent. Bar $=10 \mu \mathrm{m}$. 

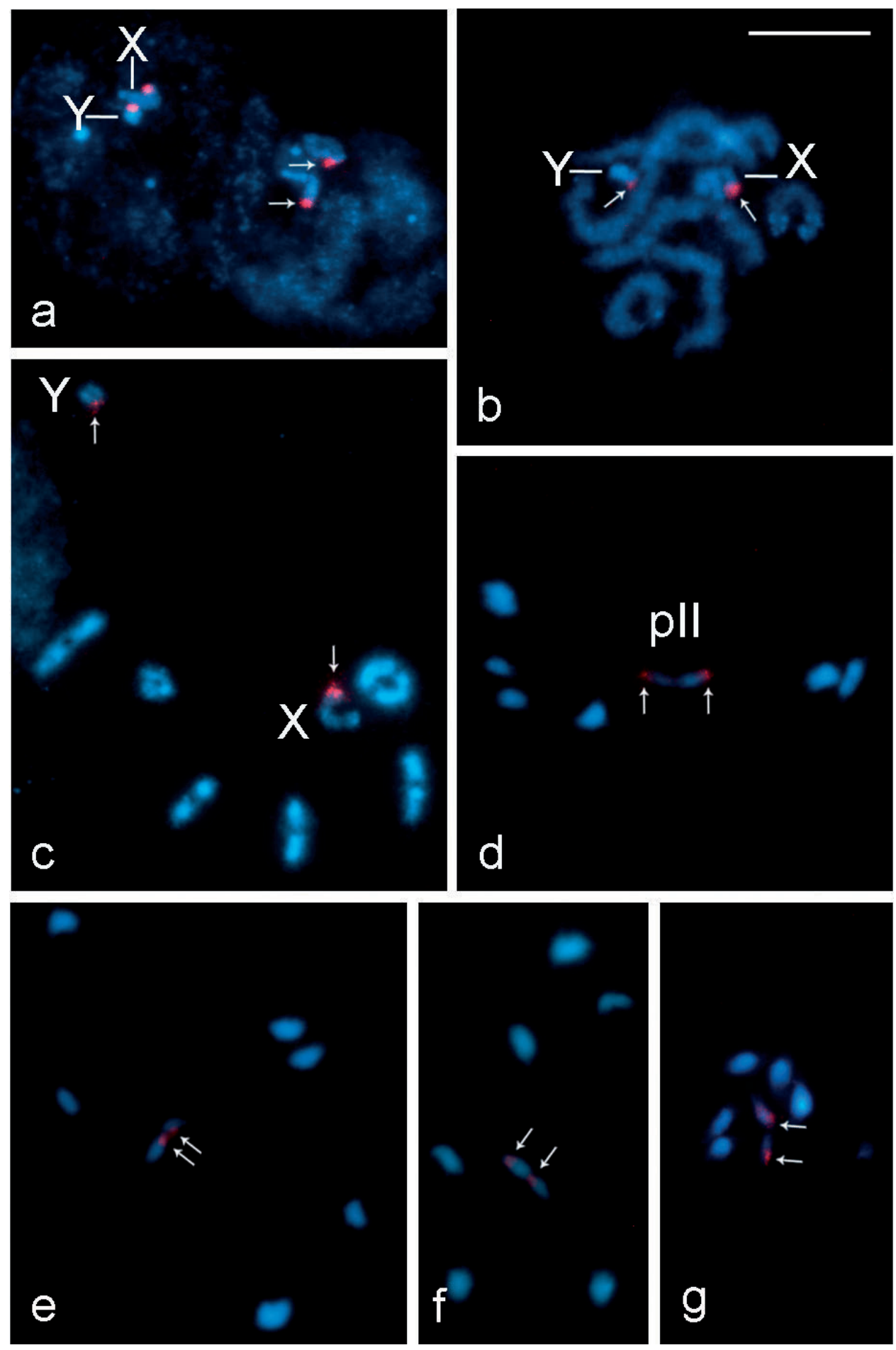

Fig. 5. Location of rDNA genes in male meiotic chromosomes of $B$. candidulum using FISH involving 18S rDNA probes (red signals, arrows). Chromosomes were counterstained with DAPI (blue). a - diffuse stage; $b$ - diplotene; $c$ - diakinesis; d-e - metaphase II; d - type XY-1 pseudo-bivalent (kinetic activity located at both ends with rDNA signal in both sex chromosomes); e - type XY-2 pseudo-bivalent (kinetic activity located at both ends without rDNA signal in both sex chromosomes); $\mathrm{f}$ - type XY-3 pseudo-bivalent (kinetic activity located at end with rDNA signal in X chromosome and at end without rDNA signal in Y chromosome); $g$ - type XY-4 pseudo-bivalent (kinetic activity located at end without rDNA signal in X chromosome and at end with rDNA signal in Y chromosome). $\mathrm{pII}=$ pseudo-bivalent. Bar $=10 \mu \mathrm{m}$.

ed at end with rDNA signal in $\mathrm{X}$ chromosome and at end without rDNA signal in Y chromosome; Fig. 5f), and Type XY-4 (kinetic activity located at end without rDNA signal in $\mathrm{X}$ chromosome and at end with rDNA signal in Y chromosome; Fig. 5g). The frequencies observed in the second metaphase revealed that the kinetic activity was indeed a random process ( 15 cells for Type XY-1; 10 cells for Type $\mathrm{XY}-2 ; 16$ cells for Type XY-3; 5 cells for Type XY-4; $\chi^{2}=$ $6,696, \mathrm{df}=3, P=0.0823)$. 


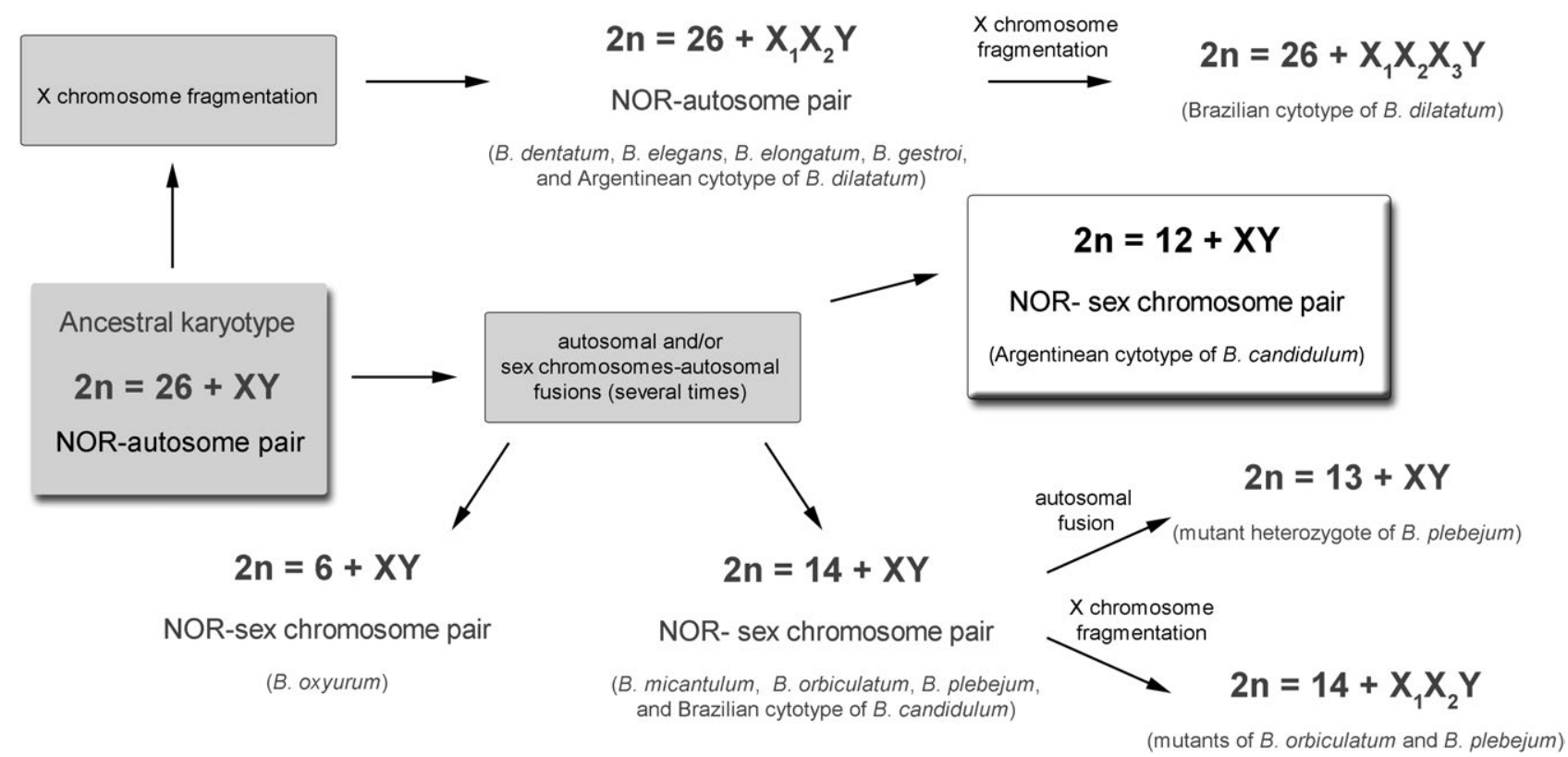

Fig. 6. Hypothetical proposal of evolution in genus Belostoma, following two ways of karyotype evolution (modified from Chirino et al., 2013).

\section{DISCUSSION}

The most remarkable cytological features observed in specimens of $B$. candidulum from Argentina as here studied were a lower novel chromosome complement $2 \mathrm{n}=12+$ $\mathrm{XY} / \mathrm{XX}$ (male/female sex chromosomes) and the large size of one pair of autosomes. The specimens examined were also seen to show heterochromatic blocks in both autosomal and $\mathrm{X}$ chromosomes, a Y chromosome with mainly C-positive banding, and a secondary constriction in the $\mathrm{X}$ chromosome. Until now, all Brazilian male specimens of this giant water bug species showed $2 n=16=14+X Y$, with the karyotype composed of four large, nine medium, and one small chromosomes (Bardella et al., 2012). Our results, in contrast, revealed that Argentinean and Brazilian populations have different diploid numbers and chromosomal features.

Argentinean and Brazilian samples are geographically separated by long distances (from $900 \mathrm{~km}$ to $2,805 \mathrm{~km}$ ) and restricted to small geographic areas showing a patchy distribution (Ribeiro, 2007; Ribeiro \& Estévez, 2009). In the present study, the specimens of $B$. candidulum were collected outside the regional distribution reported for this species in Argentina (Ribeiro, 2007; Ribeiro \& Estévez, 2009). As far as is known, the distribution areas of these two populations do not overlap, i.e. are allopatric. Given the isolation of their habitats, the limited dispersal potential, the holokinetic nature of the chromosomes, and the presence of fixed chromosomal variants, Argentinean and Brazilian B. candidulum populations should be considered as two chromosomal races or two cryptic species.

Autosomal fusions and autosomal and sex chromosome fragmentations have seemingly played the most important role in chromosomal evolution in Heteroptera (Ueshima, 1979; Manna, 1984; Thomas, 1987; Papeschi 1994, 1996;
Pérez et al., 2004). The cytogenetic data available for $B e-$ lostoma suggest that the karyotype evolution within this genus has proceeded through fragmentation of the atavic $\mathrm{X}$ chromosome, increase in heterochromatin content and autosomal and/or sex chromosome fusions (Papeschi, 1988, 1994, 1996; Papeschi \& Bressa 2006; Bardella et al., 2012; Chirino et al., 2013). Autosomal fusions may be favoured from an evolutionary point of view as a mechanism for retaining super-genes. Since each autosomal bivalent has a single chiasma, the fusion of two non-homologous autosomal pairs and the further restriction to a single crossingover in the fused autosomal pair, implies a reduction in the overall frequency of recombination. Thus, segregation of co-adapted and selectively favoured alleles is prevented. Consequently, it is highly likely that the karyotype of $B$. candidulum originated from the ancestral complement through several fusions among pairs of autosomes, as well as by the fusion of the $\mathrm{X}$ and $\mathrm{Y}$ chromosomes with the ancestral NOR-autosomal pair, making that rDNA genes were present in both $\mathrm{X}$ and $\mathrm{Y}$ sex chromosomes (Fig. 6). This hypothesis is supported by the existence of an inverse relationship between chromosome size and chromosome number (Papeschi, 1988, 1992).

This present study also revealed a direct relationship between chromosome size and frequency of chiasmata, in which the largest autosomal bivalent showed one or two terminal chiasmata at the same frequency. The presence of one or two chiasmata resulted in three interesting cytogenetic characteristics in meiosis, namely: (i) the presence of rod, ring and V-shaped bivalents; (ii) rod bivalents orientated axially but ring bivalents orientated equatorially at metaphase I; and (iii) when the ring bivalent released one of their chiasmata, it adopted an axial orientation.

The presence of ring and V-shaped bivalents at diakinesis-metaphase I have previously been shown in giant wa- 
ter bugs of the genus Belostoma (Papeschi \& Bidau, 1985; Papeschi, 1988, 1994, 1996; Papeschi \& Bressa, 2006; Bardella et al., 2012) as well as other heteropteran species with reduced chromosome complements (Camacho et al., 1985; Mola \& Papeschi, 1993; Bressa et al., 1998, 1999, 2001, 2002a, b, 2005; Jacobs \& Liebenberg, 2001; Rebagliati et al., 2001; Jacobs \& Groeneveld, 2002; Papeschi et al., 2003; Franco et al., 2006; Rebagliati \& Mola, 2010; Poggio et al., 2011). Therefore, all reports obtained from bivalents with two chiasmata stated that ring-bivalents congressed to the metaphase I plate showing holokinetic behaviour. In many cases, the ring bivalent separates at one chromosomal end and the homologous chromosomes remain associated by the second chiasma, maintaining an end-to-end association. Afterwards, the kinetic activity involved the terminal regions attaching to the spindle, and the bivalent showed a V-shaped morphology followed by rod-like configuration. Conversely, in a few cases, when the ring bivalent had a repetitive DNA sequences adjacent to the NORs in a medial position in both homologous chromosomes, microtubule bundles interact with the entire length of them and no chiasma was released, the NORs appeared at opposite poles and attached to the spindle fibres, and the bivalent maintained a ring-shape configuration (Papeschi et al., 2003).

In the Argentinean male specimens of B. candidulum, when the largest autosomal bivalent showed two chiasmata but had no NORs, half of the ring bivalents released one chiasma and the holokinetic interaction with the spindle became telokinetic at late metaphase. On the other hand, when the ring bivalent was stabilized at the metaphase plate maintaining both chiasmata, the bivalent did not open, nor did it adopt the V-shaped morphology; thus, the ring bivalent kept a holokinetic interaction with the spindle. This being so, the ring-shaped bivalent should have some mechanism/s to ensure its attachment to the spindle fibres; other alternative sites, not only terminal regions and secondary constrictions or sites next to them, would be able to acquire kinetic activity. It cannot be discounted that these alternative sites for microtubule attachment are also functional in rod bivalents. In these bivalents, the interaction between the alternative sites and the microtubules would be weaker and surpassed by the terminal regions (Papeschi et al., 2003).

In $B$. candidulum from Argentina, characterization of heterochromatin revealed very scarce $\mathrm{C}$-positive dots at terminal and interstitial positions along three autosomal bivalents. The C-banding pattern was in agreement with previous observations made for other species of the genus Belostoma, with respect to an inverse relationship between the size of the chromosomes and the amount and size of Cpositive bands (Papeschi, 1988, 1992). Species with high chromosome numbers $\left(2 \mathrm{n}=26+\mathrm{X}_{1} \mathrm{X}_{2} \mathrm{Y}\right)$ have several and/or conspicuous C-positive bands, whereas those with reduced diploid numbers $(2 \mathrm{n}=6+\mathrm{XY}, 2 \mathrm{n}=12+\mathrm{XY}, 2 \mathrm{n}$ $=14+\mathrm{XY}$ ) exhibit few and very small $\mathrm{C}$-positive dots and bands (Papeschi, 1988, 1991, 1992, 1994, 1995; Papeschi $\&$ Bressa, 2006; Chirino et al., 2013; this study). The use of
C-banding to identify content, location and distribution of constitutive heterochromatin, to detect heteromorphisms and to distinguish homologues is noteworthy, since it provides information about the chromosome organization, which is highly valuable when studying karyotype evolution. Thus, we hypothesize that the ancestral male karyotype, $2 n=26+X Y$, was characterized by its scarce C-positive heterochromatin and, from this karyotype, two events occurred, namely: (a) an increase in heterochromatin content in species with multiple sex chromosome systems after the fragmentation of the original $\mathrm{X}$ chromosome; and (b), a preservation of scarce heterochromatin content in species with reduced diploid numbers, since the increase of C-positive heterochromatin was restricted through the several fusions produced between autosomes and/or sex chromosomes.

FISH experiments using $18 \mathrm{~S}$ rDNA probes revealed a single rDNA cluster located at one terminal region of both sex chromosomes. In addition, fluorescent banding revealed a DAPI-dull/CMA-bright band at one terminal position on the $\mathrm{X}$ and $\mathrm{Y}$ chromosomes, indicating the presence of CG-rich sequences. Since CG-rich constitutive heterochromatin often occurs in the NOR regions (Papeschi et al., 2003; Rebagliati et al., 2003; Cattani et al., 2004; Cattani \& Papeschi, 2004; Papeschi \& Bressa, 2006; Criniti et al., 2009; Poggio et al., 2011; Chirino et al., 2013), we suggest that these two bands on both sex chromosomes could be associated with two rDNA clusters revealed by rDNAFISH. These results support our hypothesis that species with simple sex chromosome systems possesses the NOR regions in both $\mathrm{X}$ and $\mathrm{Y}$ chromosomes, whereas in species with multiple sex chromosome systems, the NOR is positioned in one autosomal pair only (Fig. 6). Moreover, this study provides further evidence that kinetic activity in $\mathrm{X}$ and $\mathrm{Y}$ chromosomes is randomly located on one of the two sex chromosome ends, and that it is independent of the end selected in the other sex chromosome; therefore both terminal regions of each of them could be kinetically active at the second meiotic division. FISH experiments hence provide a consistent marker to analyse the behaviour of chromosomes during meiosis (Papeschi et al., 2003; Poggio et al., 2011; present study).

Lastly, our results as presented here showed that the determination of the number and location of C-positive, DAPI- and CMA-bands, and the number and location of the NORs make them essential cytological markers since the lack of a primary constriction and/or secondary constrictions in organisms with holokinetic chromosomes has hampered cytogenetic studies and a properly chromosome identification. As a result, these techniques are clearly very useful tools for the study of the karyotype structure, meiotic behaviour and chromosome evolution in groups with holokinetic chromosomes; use of such approaches may also contribute to the analysis of changes in karyotype related to the evolutionary process and to understand taxonomic relationships. The genus Belostoma surely constitutes a very interesting group from a cytogenetic point of view, since it exhibits a great variety of chromosome 
complements with simple and multiple sex chromosome systems, and the comparative study of the karyological features of this genus (Paspeschi \& Bressa, 2006; Chirino et al., 2013) could well be used for systematic and ecological/evolutionary studies of considerable interest.

ACKNOWLEDGEMENTS. We thank A.L. Estévez for the taxonomic determination of the specimens and $\mathrm{H}$. Loxdale for editorial improvements to the MS. This work was financed by grants UBACyT W917 of University of Buenos Aires (UBA), and PIP 0281 of Consejo Nacional de Investigaciones Científicas y Técnicas (CONICET) from Argentina. M.G.C. and M.J.B. thank the Agencia Nacional de Promoción Científica y Tecnológica (ANPCyT), CONICET, UBA, and Universidad Nacional de Quilmes (UNQ). This study was carried out thanks to the permission of the Administración de Parques Nacionales (APN) and the Parque Nacional El Palmar.

\section{REFERENCES}

Analytycal Software 1998: Statistix for Windows. Version 2.0. Tallahassee, FL, USA.

Bardella V.B., Dias A.L., Giuliano-Caetano L., Ribeiro J.R.I. \& DA Rosa R. 2012: Sex chromosome differentiation in Belostoma (Insecta: Heteroptera: Belostomatidae). - Genet. Mol. Res. 11: 2476-2486.

Bressa M.J., Papeschi A.G., Mola L.M. \& Larramendy M.L. 1998: Meiotic studies in Largus rufipennis (Castelnau) (Largidae, Heteroptera). II. Reciprocal translocation heterozygosity. - Caryologia 51: 253-264.

Bressa M.J., Papeschi A.G., Mola L.M. \& Larramendy M.L. 1999: Meiotic studies in Dysdercus Guérin Meneville 1831 (Heteroptera: Pyrrhocoridae). I. Neo-XY in Dysdercus albofasciatus Berg 1878, a new sex chromosome determining system in Heteroptera. - Chromosome Res. 7: 503-508.

Bressa M.J., Papeschi A.G., Mola L.M. \& Larramendy M.L. 2001: Autosomal univalents as a common meiotic feature in Jadera haematoloma (Herrich-Schaeffer, 1847) and Jadera sanguinolenta (Fabricius, 1775) (Heteroptera, Rhopalidae: Rhopalinae). - Eur. J. Entomol. 98: 151-157.

Bressa M.J., Papeschi A.G., Mola L.M. \& Larramendy M.L. 2002a: Meiotic studies in Lygaeus alboornatus Blanchard 1852 (Heteroptera: Lygaeidae: Lygaeinae). - Caryologia 55: $15-19$.

Bressa M.J., Fumagalli E., Ituarte S., Frassa M.V. \& LarRAMENDY M.L. 2002b: Meiotic studies in Dysdercus Guérin Méneville, 1831 (Heteroptera: Pyrrhocoridae). II. Evidence of variations in the diffuse stage between wild and laboratory inbred populations of Dysdercus chaquensis Freiberg, 1948. Hereditas 137: 125-131.

Bressa M.J., Larramendy M.L. \& PAPeschi A.G. 2005: Heterochromatin characterization in five species of Heteroptera. Genetica 124: 307-317.

Bressa M.J., Papeschi A.G., VítKová M., KubíčKová S., Fuková I., Pigozzi M.I. \& Marec F. 2009: Sex chromosome evolution in cotton stainers of the genus Dysdercus (Heteroptera: Pyrrhocoridae). - Cytogenet. Genome Res. 125: 292-305.

CAmacho J.P.M., Belda J. \& CABrero J. 1985: Meiotic behaviour of the holocentric chromosomes of Nezara viridula (Insecta, Heteroptera) analysed by C-banding and silver impregnation. - Can. J. Genet. Cytol. 27: 490-497.

Cattani M.V. \& Papeschi A.G. 2004: Nucleolus organizing regions and semi-persistent nucleolus during meiosis in Spartocera fusca (Thunberg) (Coreidae, Heteroptera). - Hereditas 140: $105-111$.
Cattani M.V., Greizerstein E.J. \& Papeschi A.G. 2004: Male meiotic behaviour and nucleolus organizer regions in Camptischium clavipes (Fabr.) (Coreidae, Heteroptera) analyzed by fluorescent banding and in situ hybridization. - Caryologia 57: 267-273.

Chirino M.G., Papeschi A.G. \& Bressa M.J. 2013: The significance of cytogenetics for the study of karyotype evolution and taxonomy of water bugs (Heteroptera, Belostomatidae) native to Argentina. - Comp. Cytogenet. 7: 9-27.

Criniti A., Simonazzi G., Cassanelli S., Ferrari M., Bizzaro D. \& MANICARDI G.C. 2009: Distribution of heterochromatin and rDNA on the holocentric chromosomes of the aphids Dysaphis plantaginea and Melanaphis pyraria (Hemiptera: Aphididae). - Eur. J. Entomol. 106: 153-157.

DANIEL W.W. 1990: Applied Nonparametric Statistics. PWSKent, Devon, UK, 635 pp.

Franco M., Bressa M.J. \& Papeschi A.G. 2006: Karyotype and male meiosis in Spartocera batatas (Fabricius) and meiotic behaviour of multiple sex chromosomes in Coreidae, Heteroptera. - Eur. J. Entomol. 103: 9-16.

Fuková I., Nguyen P. \& Marec F. 2005: Codling moth cytogenetics: karyotype, chromosomal location of rDNA, and molecular differentiation of sex chromosomes. - Genome 48: 1083-1092.

GLASER R.W. 1917: Ringer solutions and some notes on the physiological basis of their ionic composition. - Comp. Biochem. Physiol. 2: 241-289.

Heckman C.W. 2011: Belostomatidae. In: Encyclopedia of South American Aquatic Insects: Hemiptera - Heteroptera. Illustrated Keys to Known Families, Genera, and Species in South America. Springer, Dordrecht, Heidelberg, London, New York, pp. 393-434.

Jacobs D.H. \& Groenveld H.T. 2002: Cytogenetics and karyotype evolution of the genus Silvacoris Jacobs (Heteroptera: Aradidae: Carventinae) with a description of a statistical method to compare karyotypes. - Cytologia 67: 159-168.

JACoBs D.H. \& Liebenberg H. 2001: Cytogenetics of Adamanotus uncotibialis Jacobs (Heteroptera: Aradidae). — Caryologia 54: 83-86.

LOCKWOOD A.P.M. 1961: 'Ringer' solutions and some notes on the physiological basis of their ionic composition. - Comp. Biochem. Physiol. 2: 241-289.

ManNA G.K. 1984: Chromosomes in evolution in Heteroptera. In Sharma A.K. \& Sharma A. (eds): Chromosomes in Evolution of Eukaryotic Groups. CRC Press, Boca Raton, FL, pp. 189-225.

McClung C.E. 1905: The chromosome complex of orthopteran spermatocytes. - Biol. Bull. 9: 304-340.

Mola L.M. \& PAPeschi A.G. 1993: Meiotic studies in Largus rufipennis (Castelnau) (Largidae, Heteroptera): frequency and behaviour of ring bivalents, univalents and $\mathrm{B}$ chromosomes. Heredity 71: 33-40.

Motzko D. \& Ruthmann A. 1984: Spindle membranes in mitosis and meiosis of the heteropteran insect Dysdercus intermedius. A study of the interrelationship of spindle architecture and the kinetic organization of chromosomes. - Eur. J. Cell Biol. 33: 205-216.

PAPESCHI A.G. 1988: C-banding and DNA content in three species of Belostoma (Heteroptera) with large differences in chromosome size and number. - Genetica 76: 43-51.

PAPESCHI A.G. 1991: DNA content and heterochromatin variation in species of Belostoma (Heteroptera, Belostomatidae). - Hereditas 115: 109-114.

PAPeschi A.G. 1992: Estudios Citogenéticos y Evolutivos en Heteroptera. Doctoral Thesis, Universidad de Buenos Aires, 259 pp. [in Spanish]. 
PAPESCHI A.G. 1994: Chromosome rearrangements in Belostoma plebejum (Stål) (Belostomatidae, Heteroptera). - Caryologia 47: 223-230.

PAPesChI A.G. 1995: Correspondence between C-banding and Ag-NOR in the sex chromosomes of Belostoma oxyurum (Belostomatidae, Heteroptera). - Cytologia 60: 291-295.

PAPesChi A.G. 1996: Sex chromosome polymorphism in species of Belostoma (Belostomatidae, Heteroptera). - Hereditas 124: 269-274.

PAPESCHI A.G. \& BiDAu C.J. 1985: Chromosome complement and male meiosis in four species of Belostoma Latreille (Heteroptera: Belostomatidae). - Braz. J. Genet. 8: 249-261.

PAPESCHI A.G. \& Bressa M.J. 2006: Evolutionary cytogenetics in Heteroptera. - J. Biol. Res. 5: 3-21.

Papeschi A.G., Mola L.M., Bressa M.J., Greizerstein E.J., Lia V. \& Polhemus L. 2003: Behaviour of ring bivalents in holokinetic systems: alternative sites of spindle attachment in Pachylis argentinus and Nezara viridula (Heteroptera). - Chromosome Res. 11: 725-733.

Pérez R., Calleros L., Rose V., Lorca M. \& Panzera F. 2004 Cytogenetic studies on Mepraia gajardoi (Heteroptera: Reduviidae). Chromosome behaviour in a spontaneous translocation mutant. — Eur. J. Entomol. 101: 211-218.

Poggio M.G., Bressa M.J. \& PAPeschi A.G. 2011: Male meiosis, heterochromatin characterization and chromosomal location of rDNA in Microtomus lunifer (Berg, 1900) (Hemiptera: Reduviidae: Hammacerinae). - Comp. Cytogenet. 5: 1-22.

Polnemus J.T. \& Polnemus D.A. 2008: Global diversity of true bugs (Heteroptera: Insecta) in freshwater. - Hydrobiologia 595: 379-391.

Rebagliati P.J. \& Mola L.M. 2010: Meiotic behavior and karyotypic variation in Acledra (Pentatomidae, Heteroptera). Genet. Mol. Res. 9: 739-749.

Rebagliati P.J., Mola L.M. \& Papeschi A.G. 2001: Karyotype and meiotic behaviour of the holokinetic chromosomes of six Argentine species of Pentatomidae (Heteroptera). - Caryologia 54: 339-347.
Rebagliati P.J., Papeschi A.G. \& Mola L.M. 2003: Meiosis and fluorescent bandings in Edessa meditabunda and Edessa rufomarginata (Heteroptera: Pentatomidae: Edessinae). — Eur. J. Entomol. 100: 11-18.

Reeves A. \& Tear J. 2000: MicroMeasure for Windows, version 3.3. (Free program, distributed by the authors via http://www. colostate.edu/Depts/Biology/Micro-Measure).

Ribeiro J.R. 2007: A review of the species of Belostoma Latreille, 1807 (Hemiptera: Heteroptera: Belostomatidae) from the four southeastern Brazilian states. - Zootaxa 1477: 1-70.

Ribeiro J.R. \& Estévez A.K. 2009: The small species of Belostoma Latreille (Heteroptera, Belostomatidae). III. A revision of oxyurum group, with a new species from Brazil and description of the male of B. noualhieri Montandon. - Rev. Bras. Entomol. 53: 207-215.

SÁEz F.A. 1960: El empleo de la hematoxilina acética o propiónica para el estudio de los cromosomas con la técnica de aplastamiento. - Com. Soc. Biol. Montevideo (Mimeographed): 1.

Sahara K., Marec F. \& Traut W. 1999: TTAGG telomeric repeats in chromosomes of some insects and other arthropods. - Chromosome Res. 7: 449-460.

SCHNACK J.A. 1976: Los Belostomatidae de la República Argentina (Hemiptera). In Ringuelet R.A. (ed.): Fauna de Agua Dulce de la República Argentina. Fundación para la Educación la Ciencia y la Cultura, Buenos Aires, pp. 1-66.

Suja J.A., Del Cerro A.L., Page J., Rufas J.S. \& Santos J.L. 2000: Meiotic sister chromatid cohesion in holocentric sex chromosomes of three heteropteran species is maintained in absence of axial elements. - Chromosoma 109: 35-43.

Thомas D.B.J. 1987: Chromosome evolution in the Heteroptera (Hemiptera): agmatoploidy versus aneuploidy. - Ann. Entomol. Soc. Am. 80: 720-730.

Traut W. 1976: Pachytene mapping in the female silkworm Bombyx mori L. (Lepidoptera). - Chromosoma 58: 275-284.

Ueshima N. 1979: Hemiptera II: Heteroptera. In John B. (ed.): Animal Cytogenetics. Vol. 3. Insecta 6. Borntraeger, Berlin, $\mathrm{v}+117 \mathrm{pp}$.

Received November 18, 2013; revised and accepted December 31, 2013 Prepublished online March 14, 2014 